\title{
Does environmental science crowd out non-epistemic values?
}

\author{
Kinley Gillette ${ }^{\mathrm{a}}$, S. Andrew Inkpen ${ }^{\mathrm{b}}$, C. Tyler DesRoches ${ }^{\mathrm{c}, *}$ \\ a Department of Philosophy, University of British Columbia, 1866 Main Mall, Buchanan E370, Vancouver, BC, Canada, V6T 1Z1 \\ ${ }^{\mathrm{b}}$ Department of Philosophy, Mount Allison University, 63D York St, Sackville, New Brunswick, E4L 1G9, Canada \\ ${ }^{\mathrm{c}}$ School of Sustainability and School of Historical, Philosophical and Religious Studies, Arizona State University, Wrigley Hall, 800 Cady Mall \#108, Tempe, \\ AZ, 85281, USA
}

\section{A R T I C L E I N F O}

\section{Article history:}

Received 8 July 2020

Received in revised form

24 November 2020

Accepted 21 January 2021

\section{Keywords:}

Philosophy of science

Philosophy of interdisciplinary science

Environmental science

Non-epistemic values

\begin{abstract}
A B S T R A C T
While no one denies that science depends on epistemic values, many philosophers of science have wrestled with the appropriate role of non-epistemic values, such as social, ethical, and political values. Recently, philosophers of science have overwhelmingly accepted that non-epistemic values should play a legitimate role in science. The recent philosophical debate has shifted from the value-free ideal in science to questions about how science should incorporate non-epistemic values. This article engages with such questions through an exploration of the environmental sciences. These sciences are a mosaic of diverse fields characterized by interdisciplinarity, problem-orientation, policy-directedness, and ubiquitous nonepistemic values. This article addresses a frequently voiced concern about many environmental science practices: that they 'crowd out' or displace significant non-epistemic values by either (1) entailing some non-epistemic values, rather than others, or by (2) obscuring discussion of non-epistemic values altogether. With three detailed case studies - monetizing nature, nature-society dualism, and ecosystem health - we show that the alleged problem of crowding out emerges from active debates within the environmental sciences. In each case, critics charge that the scientific practice in question displaces nonepistemic values in at least one of the two senses distinguished above. We show that crowding out is neither necessary nor always harmful when it occurs. However, we do see these putative objections to the application of environmental science as teaching valuable lessons about what matters for successful environmental science, all things considered. Given the significant role that many environmental scientists see for non-epistemic values in their fields, we argue that these cases motivate lessons about the importance of value-flexibility (that practices can accommodate a plurality of non-epistemic values), transparency about value-based decisions that inform practice, and environmental pragmatism.
\end{abstract}

(c) 2021 Elsevier Ltd. All rights reserved.

\section{Introduction}

Philosophers of science have long recognized the role of values in science (Rudner 1953). Shared epistemic values, such as consistency, scope, fruitfulness, generality, and simplicity, are indispensable to the scientific enterprise itself (Kuhn 1962, 1977). They are the basis for the rules that determine what constitutes acceptable scientific practice. While no one denies that science depends on epistemic values, many philosophers of science have wrestled with the appropriate role of non-epistemic values, such as social, ethical, and political values (see Alexandrova 2018; Brown

\footnotetext{
* Corresponding author. School of Sustainability and School of Historical, Philosophical and Religious Studies, Arizona State University, Wrigley Hall, 800 Cady Mall \#108, Tempe, AZ, 85281, USA.

E-mail address: tyler.desroches@asu.edu (C.T. DesRoches).
}

2013; Douglas 2013; Elliott and McKaughan 2013; Elliott and Willmes 2013; Longino 1990).

While the value-free ideal-the view that science should be insulated from non-epistemic values and that value-ladenness compromises objectivity-figured prominently among many philosophers of science during the mid-twentieth century, most philosophers of science today accept that some non-epistemic values have a legitimate role to play in science. Under the right conditions, objectivity and value-ladenness can be reconciled (e.g., Alexandrova 2018; Elliott and Steel 2017). The debate has thus shifted away from issues regarding the value-free ideal and towards questions about how some non-epistemic values can be incorporated into the scientific enterprise itself.

This article engages with such questions by exploring the environmental sciences, the focus of this Special Issue. These sciences are a mosaic of diverse fields characterized by interdisciplinarity, problem-orientation, policy-directedness, and 
ubiquitous non-epistemic values. Our aim in this article is to address a frequently voiced concern about many environmental science practices: that they 'crowd out' or displace significant nonepistemic values by either entailing some non-epistemic values, rather than others, or by obscuring discussion of non-epistemic values altogether. For instance, does assigning monetary value to some parts of nature crowd out the putative intrinsic value of nature? Is the concept of 'ecosystem health' problematically valueladen for environmental science? We analyze concerns about crowding out arising in three different contexts and ask what they teach us about the environmental sciences.

Evaluating the overall success of the environmental sciences requires understanding and addressing this putative problem. While other philosophers of science, such as Miles MacLeod and Michiru Nagatsu (2016), focus on the epistemic values or collaborative gains resulting from the interdisciplinary exchange that characterizes the environmental sciences, one might reasonably suppose that even if an environmental science were calibrated for excellent predictive power, explanatory scope, and reliability, many complementary questions would remain about the various ways in which non-epistemic values can and should be incorporated. Even the most epistemically favorable environmental science remains subject to the criticism that it might displace significant nonepistemic values.

We show that the alleged problem of crowding out emerges not from the ivory tower, but from active debates within the environmental sciences. As such, this article is driven by three detailed case studies, focusing on (1) the concepts of 'natural capital' and 'ecosystem services' in the interdisciplinary field of ecological economics, (2) a type of nature-society dualism (NSD) presupposed by social-ecological systems (SES) research, and (3) the use of ecosystem health measures to direct environmental policy. In each case study, critics have either charged or implied that the scientific practice in question displaces non-epistemic values in at least one of the two senses distinguished above. Critics argue, in particular, that assigning parts of nature with monetary value precludes assigning these same parts of nature with socially significant noninstrumental value, that NSD devalues either nature or society, and that measures of ecosystem health may conceal underlying debates about distinct non-epistemic values.

We take these criticisms seriously but argue that critics unjustifiably take the cases to prove too much. Reconsidering these cases, we show that crowding out is neither necessary nor always harmful when it occurs. However, we claim these putative objections to the application of environmental science as teaching valuable lessons about what matters for successful environmental science, all things considered. Given the significant role that many environmental scientists themselves see for non-epistemic values in their fields, we argue that these cases motivate lessons about the importance of value-flexibility (that practices can accommodate a plurality of non-epistemic values), transparency about value-based decisions that inform practice, and environmental pragmatism. We believe that these lessons complement epistemically-oriented studies in the philosophy of science, such as MacLeod and Nagatsu's (2016) discussion of the conditions conducive to achieving the "problem-solving goals" of collaborations, or Inkpen and DesRoches' (2020) analysis of the predictive and explanatory benefits of coupled, ecological-economic models.

Our article is structured as follows. In the next section, we discuss three case studies where the criticism of crowding out has been raised. We derive a few lessons in response to this criticism in different contexts. In Section 3, we draw on resources in the science and values literature to argue that the pertinent issue for environmental science to address is value-inflexibility and nontransparency. Finally, in Section 4, we conclude by discussing how our analysis complements existing work on successful environmental science.

\section{Three case studies}

As suggested above, critics have often worried that certain environmental science practices crowd out or displace significant non-epistemic values, and some take this to be an argument against the usefulness or success of these practices. In this section, we provide three case studies to argue that such a conclusion is unjustified. Each case is followed by a lesson that we believe the case supports. Each case builds on the lesson from the last. The first case demonstrates that non-epistemic values are not always displaced in the way that critics sometimes contend, insofar as crowding out is sensitive to context; the second demonstrates that modelling practices can, in a given context, be more flexible with regard to non-epistemic values than some scholars have recognized; and the third case demonstrates the importance of transparency about non-epistemic values. We thus take these cases to make separate but related points.

\subsection{Does monetizing nature crowd out the intrinsic value of nature?}

Ecological Economics is an interdisciplinary science that emerged as a formal institution in the 1980s, with its origins extending back to the biophysical economist, Nicholas GeorgescuRoegen's (1971) The Entropy Law and Economic Processes. ${ }^{1}$ Over the last few decades, it has become common practice for ecological economists to assign parts of nature denoted by the concepts of 'natural capital' and 'ecosystem services' with monetary or economic value. These concepts denote a rich variety of active and modifiable production processes that not only afford human beings with passive materials to be improved by labor and manufactured capital, but endows them with production processes that spontaneously generate valuable goods and services in a manner that is relatively detached from intentional human agency (DesRoches, 2018, 2019, 2020).

One classic study concluded that the Earth's entire biosphere, including a wide range of services generated by natural capital, such as the purification of water, nutrient cycling, and the detoxification of wastes, is worth between $\$ 14$ and \$54 trillion dollars, annually (Costanza et al. 1997, 2014). Economists have devised a variety of indirect methods to estimate the economic value of ecosystem services that have no market price, including willingness-to-pay surveys, the travel-cost method, replacement cost, and hedonic indices. ${ }^{2}$ These techniques appear to show that, although natural capital and ecosystem goods and services may possess no market price, they still possess economic value.

What is the motivation for ecological economists and their life scientist colleagues to monetize nature? Arguably, the central motivation has been to avoid market failure. The Cambridge resource economist Partha Dasgupta (2010) worries that if the economic value of natural capital and ecosystem services is not explicitly acknowledged, then these so-called 'natural assets' will be mismanaged. Without monetizing nature, the economic value of natural capital and ecosystem services will be underestimated or, worse, ignored altogether. If, for example, the economic value of the 'pollination services' afforded by pollinator species remains unaccounted for, then this economically significant process could be

\footnotetext{
${ }^{1}$ See Martinez-Alier and Røpke (2008a), (2008b); Røpke (2005).

2 Each of these techniques has shortcomings. For details, see Heal (2000a; 2000b) and Barbier (2011).
} 
depleted or, worse still, depleted inefficiently. Once the economic value of pollination services afforded by pollinator species is properly estimated, this information can be used to manage it like any other capital asset: to optimize its rate of return over time.

While assigning ecosystem services with economic value has, over the last few decades, become widespread, there have been many methodological and philosophical objections to this practice. ${ }^{3}$ Here, we consider only one such objection: monetizing parts of nature denoted by natural capital and ecosystem services crowds out the putative non-instrumental (or intrinsic) value of nature. Indeed, critics have long argued that assigning parts of nature with economic value involves assigning instrumental value to nature and this practice is objectionable because 'commodifying nature' risks crowding out nature's intrinsic value (see Gómez-Baggethun and Ruiz-Pérez 2011).

The most recent version of this argument is due to the ecological economist Peter A. Victor (2020). Victor argues that monetizing nature entails assigning it with instrumental value and this practice invites an exploitative attitude towards nature. We are told that the practice is objectionable because it "denies, or minimizes, the ethical value of nature itself, of individual and connected ecosystems, of non-human species and their members. These are all just capital to be valued for their utility to humans" (Victor 2020, p. 6).

Our question is the following: does assigning parts of nature with economic value (and paying for ecosystem services) necessarily crowd out significant non-epistemic values, such as the intrinsic value of nature? By considering literature on the moral limits to free markets, we will argue that the answer to this question is no. Instead, we maintain that scholars who are both for and against the monetization of ecosystem services would do well to recognize their shared goal of conserving the parts of nature denoted by natural capital and ecosystem services and judge the merits of any proposed strategy to achieve this goal, including the monetization of nature, on their efficaciousness, which is to say, the best empirical evidence available.

Many political philosophers, including Elizabeth Anderson (1990; 1993), Margaret Radin (1996), Michael Sandel (2012), and Michael Walzer (1983), have argued that there are moral limits to free markets because the distribution of goods should be consistent with their social meaning. On the whole, these scholars argue that the market is not a neutral mechanism for distributing goods and services but involves treating goods in a certain way: as commodities. And, because not all goods in human life should be treated as such, these scholars argue that there is a class of goods that should not be for sale.

Consider, for example, friendship. Sandel (2012) argues that friendship is not the kind of good that can be bought and sold without degrading or corrupting it. As he puts it, "the money that buys the friendship dissolves it, or turns it into something else" $(2012,94)$. One might be able to pay another person for the "services' that would be expected from a friend, but the friendship itself, if it is a genuine relationship between individuals, is not the kind of thing that can be bought and sold without corrupting it.

Many who object to the monetization of ecosystem services and payments for ecosystem services object for the same reason that Sandel raises with respect to friendship. Making payments for ecosystem services involves treating parts of nature as a mere commodity - as something that possesses instrumental value alone - and this is problematic because the parts of nature denoted by natural capital and ecosystem services possess intrinsic value and, therefore, ought to be respected and not treated as a

\footnotetext{
${ }^{3}$ On the prevalence of this practice, see Costanza et al. (1997); Costanza et al. 2014; Barbier 2011; Helm 2015; Daily 1997; Kareiva et al. 2011.
}

commodity. Monetizing nature is incompatible with this putative proper mode of valuation.

In response to this argument, one might recognize that the social meanings of goods are frequently contested (Satz 2010). Different individuals and moral communities tend to assign a wide variety of social meanings and values to the same goods. Without a widespread consensus on the social meaning of specific goods, such as natural capital and ecosystem services, such meaning cannot be expected to serve as a benchmark for deciding when some item should not be for sale.

Setting aside the question of whether parts of nature really do possess intrinsic value, we might ask whether assigning nature with economic value and accepting payment for ecosystem services - the commodification of nature - crowds out the putative intrinsic value of nature. Indeed, there appears to be only a tenuous connection between the social meaning, including intrinsic value, that people assign to goods and the distribution of goods by the market. While scholars such as Anderson, Walzer, Radin, and Sandel, worry that buying and selling certain socially significant goods might crowd out other important ways of valuing such items, others have argued that "the market price is rarely the direct expression of our evaluative attitudes towards goods" (Satz 2010, p. 82).

Take, for example, the buying and selling of sacred texts. Does the atheist bookstore owner who sells religious texts undermine the special value assigned to the Bible for devout Christians? When such a text is treated as a mere commodity by some people, does this treatment undermine other significant ways of valuing such items? On the contrary, buying and selling sacred texts in the marketplace does not seem to displace the special social meaning among those for whom it matters. Instead, the same item can be treated differently by market participants involved in the same transaction. The atheist bookstore owner can treat a religious text as a mere commodity, believing that the item has no value apart from its contribution to her profit margin, while this attitude has no effect on the religious buyer's valuation of the same object.

The same conclusion follows for 'payments for ecosystem services' (Farley and Costanza 2010). Consider another example. Jim owns 500 acres of land in Costa Rica. His land consists of virgin rainforest replete with natural springs. Jim, a preservationist, believes that some parts of nature, including his rainforest, possess intrinsic value. While Jim would, other things being equal, prefer to preserve all of his rainforest, other things are not equal. He must make a living from his land to support his family. So, Jim gives serious consideration to his next best option: selectively logging his forest and producing some organic coffee beans for a lucrative export market destined for Western Europe.

Fortunately for Jim, a new option becomes available before he wields his axe. After hearing that Jim was planning to clear a part of his rainforest, which would entail redirecting the water flowing from his springs, Jim's neighbor, Amy, makes Jim an offer. Amy offers to pay Jim to ensure the water which currently flows from his springs to her property continues unabated. Unlike Jim, Amy assigns no intrinsic value whatsoever to nature. She believes nonhuman nature possesses mere instrumental value. While Jim hesitates to accept payments from Amy, nothing makes him happier than the prospect of supporting his family and conserving his 500acre rainforest paradise simultaneously. Jim accepts Amy's offer. As a consequence of this transaction, both parties are made better-off by their own subjective standards.

Both of the foregoing examples reveal that the social meanings assigned to some goods need not be undermined when those goods are treated as commodities. In the second example, assigning ecosystem services with economic value and accepting payment for such services does not necessarily crowd out significant modes of 


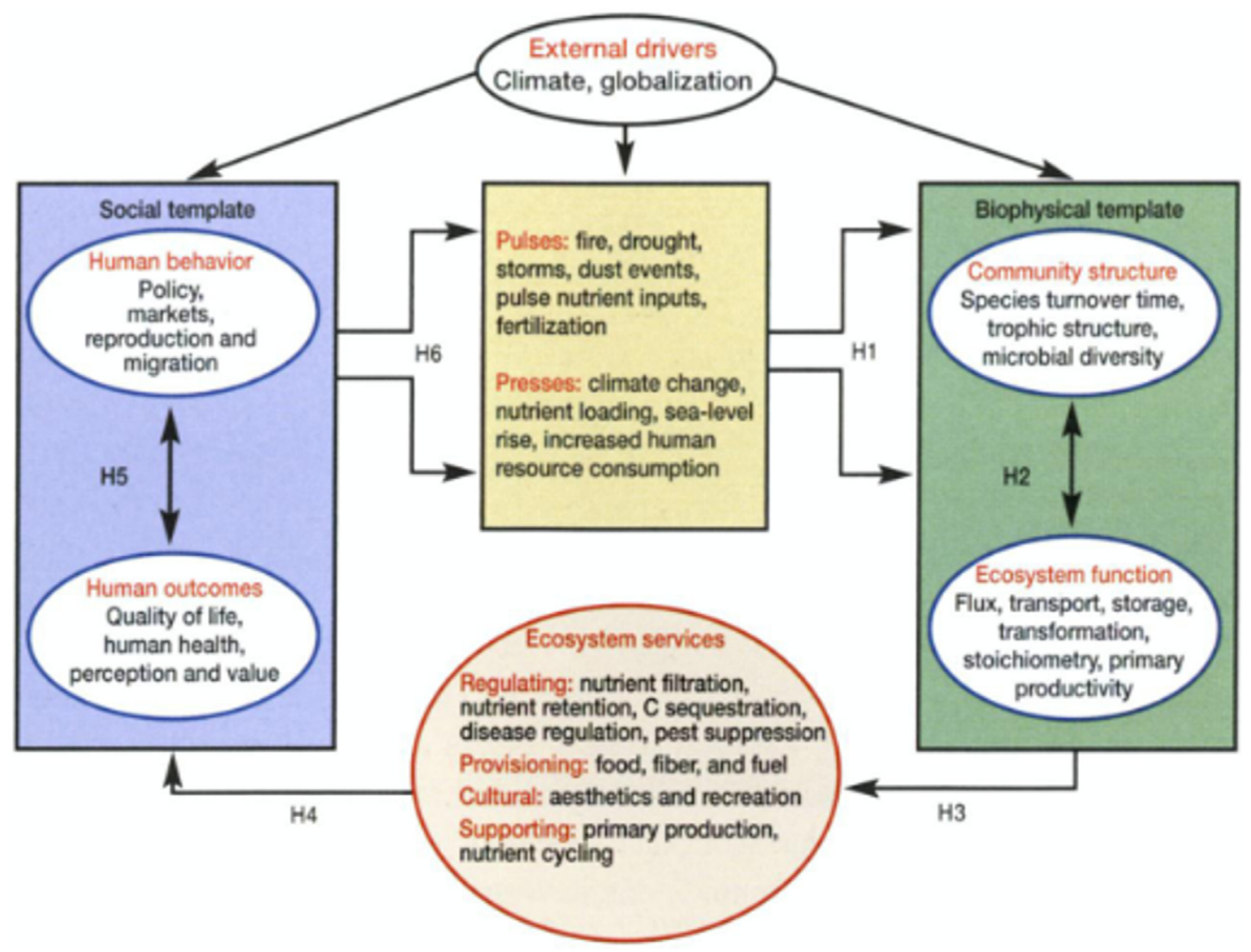

Fig. 1. "Press-Pulse Dynamics" (PPD) Framework (Collins et al. 2011, p. 353).

valuation, such as the intrinsic value of nature. After all, Jim accepts Amy's payments and this transaction does not undermine Jim's mode of valuation with respect to his land. Jim continues to assign intrinsic value to his parcel of paradise and gets paid to conserve it, too. While some might criticize Amy for an inappropriate attitude directed towards nature, her attitude and actions (payments) do not extinguish Jim's evaluative judgment.

With that being said, crowding out non-epistemic values can still occur. Consider an alternative version of the example of Jim and Amy, in which Jim not only believes that his rainforest has intrinsic value, but that monetizing it would necessarily devalue it. In this scenario, Amy's monetization plan would crowd out Jim's strict mode of valuation. Moreover, broad social or governmental acceptance of the monetization of nature would, at the social level, crowd out Jim's mode of valuation as well.

Alternatively, suppose that Jim is still willing to accept the monetization of his rainforest under certain conditions, but that these conditions are not met. In particular, broad social or governmental acceptance of the monetization of nature forces Jim to transition some of his land to coffee production in a manner that is incompatible with his preferred mode of valuation. Jim may, of course, maintain his view that some parts of nature have intrinsic value, but if we look beyond the individual level to the social level, we observe that the prevailing norm or policy may crowd out the intrinsic valuation of nature and so force Jim to compromise on his

\footnotetext{
${ }^{4}$ Of course, it remains an open question whether the foregoing instance of socially crowding out is objectionable. The decision to monetize nature at the social level may be the result of a legitimate deliberative democratic decision-making process, for instance.
}

values. This example shows that monetizing nature might sometimes be more accomodating of different non-epistemic values at the individual level than at the social level, and that a given practice may therefore crowd out non-epistemic values in one context but not another. ${ }^{4}$

This case reveals that those concerned with the commodification of nature crowding out socially significant modes of valuation might be better served by redirecting their efforts towards answering a more pragmatic and empirical question: how effective is a given strategy, including the monetization of nature, for conserving parts of nature in a given context? After all, most environmental scientists and scholars who are concerned with the commodification of nature and ecological economists who monetize nature do in fact share one and the same goal: to help conserve the objects denoted by the concepts of natural capital and ecosystem services. As the economist Geoffrey Heal (2000a, 125) recognizes, "[the monetization of nature] is neither necessary nor sufficient for conservation. We conserve much of which we do not place economic value, and we do not conserve much that we value economically" (2000a, 125). Rather than ruling out any conservation strategy a priori, environmental scientists and critics would be better served by initially remaining neutral to the conservation of natural capital and ecosystem services, realizing that their conservation is not necessarily guaranteed by monetizing nature or assigning nature with intrinsic value.

\subsection{Nature-society dualism}

If our first case study demonstrated that crowding out does not always materialize as critics contend and is instead contextsensitive, then our second case study demonstrates that, even in 


\section{Ecological Modeling}

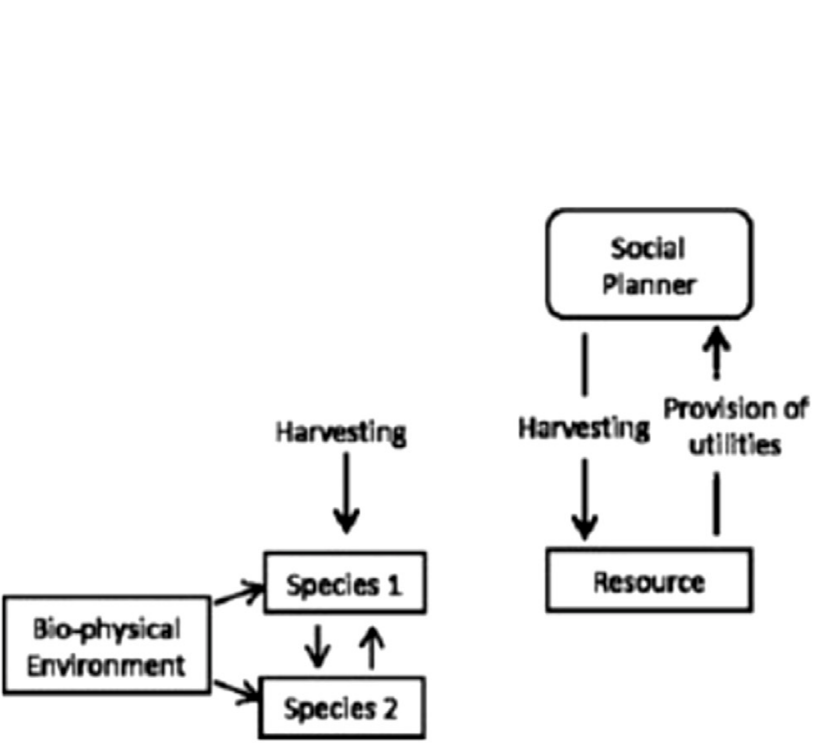

Social-ecological Modeling

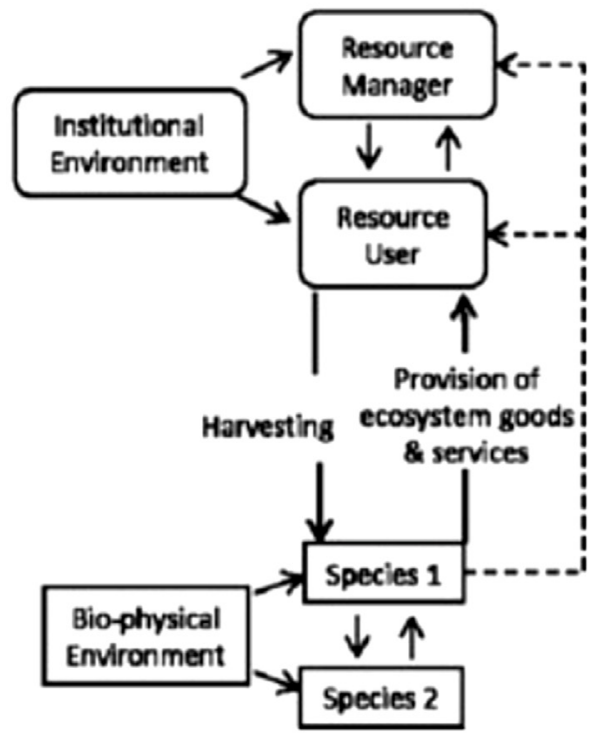

Fig. 2. Example of social-ecological systems (SES) conceptual model (Schlüter et al. 2012: 224).

a given context, at least one environmental science practice can accommodate a variety of different non-epistemic values (and so demonstrates value-flexibility). We make this point by shifting to another field in the environmental sciences: social-ecological systems (SES) research.

SES research is a growing field of interdisciplinary research (Colding and Barthel 2019). SES researchers generally aim to integrate the social and ecological sciences in order to improve understanding of the interconnections between social and ecological systems, the idea being that an improved understanding of socialecological interactions can serve the non-epistemic aim of improving environmental outcomes (e.g., Berkes and Folkes 1998; Schlüter et al., 2012). For example, many SES researchers argue that, if conservationists lack an understanding of the 'human side' of environmental problems, they will inevitably develop conservation plans that remain unimplemented (Ban et al., 2013), as in 'paper parks,' for instance (Agrawal \& Ostrom, 2006).

SES research is also characterized by its reliance on conceptual models to facilitate interdisciplinary integration. ${ }^{5}$ Conceptual models are typically qualitative and frequently take the form of diagrams that depict the interacting components of an SES (Figs. 1 and 2). The value of the models is that they provide researchers with an initial formulation of a target system's state variables, processes, etc. (e.g., Hinkel et al., 2014). Crucially, the main components are understood to be subsystems of an SES, and the subsystems are classified as either natural (e.g., ecosystems) or social (e.g., institutions) (e.g., Alberti et al., 2011; Anderies et al., 2004; Bennett et al., 2016; Collins et al., 2011). Thus, conceptual models in SES research show both that and roughly how distinct natural and social subsystems are linked. Conceptual modelling is, then, a qualitative version of what MacLeod and Nagatsu (2016) call the "coupled-model framework," insofar as it directs researchers to link models from different disciplines - in particular, ecology and various social sciences - together via the models' respective inputs

\footnotetext{
${ }^{5}$ In the SES literature, conceptual models are also sometimes called "conceptual frameworks" (Alberti et al., 2011; Berkes \& Folke 1998; Binder et al., 2013; Collins et al., 2011) or “conceptual maps” (Ostrom 2007).
}

and outputs, rather than building entirely new models with components that transcend the ecological and social sciences. Such coupling facilitates the integration of existing subsystem-specific expertise and helps define research questions that can be approached by collaborating natural and social scientists, who are designated as experts on their respective subsystems (Alberti et al., 2011; Binder et al., 2013; Heemskerk et al., 2003).

An important feature of SES research for our purposes is that its conceptual models exhibit a form of nature-society dualism (NSD), even as they depict causal interactions between social and ecological subsystems. Specifically, these models exhibit what we call classificatory NSD - that is, the treatment of nature and society as non-overlapping, or disjoint, sets. ${ }^{6}$ That the conceptual models exhibit classificatory NSD is evidenced, first, by their depiction of nature and society as separate subsystems, and, second, by the modularity of the corresponding sub-models. In short, if the submodels are separate and separable, then they represent subsystems that do not overlap, even if they causally interact. Classificatory NSD can be usefully contrasted with what we call causal $N S D$ - that is, the treatment of either nature or society as exogenous in causal interactions with the other side of the dualism (see Inkpen 2017a). ${ }^{7}$ In fact, SES research can be concisely characterized as a field that utilizes classificatory NSD, via coupled models, to overcome causal NSD, with the aim of improving environmental outcomes (see Liu et al., 2007).

Yet critics of NSD have long argued that NSD has non-epistemic costs. ${ }^{8}$ We specifically respond to two anti-NSD arguments in this case study, labelling them the natural devaluation argument and the

\footnotetext{
${ }^{6}$ Classificatory NSD is different from recognizing the distinct concepts of nature and society, because distinct sets can overlap. Classificatory NSD requires nonoverlapping sets.

7 Our definitions of these two types of dualism do not necessarily correspond to definitions of 'dualism' in other fields. Our typology of NSD is also not exhaustive.

8 To be sure, arguments against NSD in environmental ethics do not typically identify SES research as their target. Nevertheless, anti-NSD arguments are often general in scope and for that reason apply to SES research, perhaps unintentionally, as long as SES research is dualistic in the contested sense. Insofar as we identify one context - namely, SES research - in which these anti-NSD arguments fail, we provide a (perhaps neglected) counterexample to general arguments against NSD.
} 
social devaluation argument, respectively. If proponents of either argument are right, and classificatory NSD is their intended target, then conceptual modelling in SES research may, due to its classificatory NSD, crowd out the proper valuation of either nature or society, regardless of its epistemic benefits. ${ }^{9}$ We argue, however, that classificatory NSD, at least as it occurs in the context of SES research, accommodates the proper valuation of both nature and society simultaneously.

According to the natural devaluation argument, NSD is objectionable in most, if not all, contexts, because it leads to the inappropriate devaluation of nature (Meyer 1999). For example, Moore (2016a; 2016b) has argued that NSD is a 'thought-structure' that allows people to conceive of themselves as separate from nature, which in turn makes people more likely to devalue nature. For Moore (2016a), an important instance of NSD is what he calls "Green Arithmetic." Green Arithmetic is the view that, "Society plus Nature = History" (Moore 2016a). Does Green Arithmetic target classificatory NSD in particular? According to this view, the causal interaction of nature and society is given, which suggests that Moore is not objecting to causal NSD but rather classificatory NSD. That classificatory NSD is the target is also suggested by how Moore describes the alternative: "human organization as something more-than-human and less-than-social" (Moore 2016a). Given that Moore's alternative entails that the categories of nature and society overlap, it is plausible that what he thinks is objectionable about Green Arithmetic is its assumption that nature and society are nonoverlapping sets (i.e., classificatory NSD). Notably, Leopold (1949) similarly argued that the inappropriate devaluation of nature stems from a society's failure to think 'ecologically' and, in particular, the failure to think about humans as part of rather than separate from an ecological community. ${ }^{10}$

By contrast, according to the social devaluation argument, the problem with NSD is that it crowds out a proper valuation of society rather than nature. Typically, the argument takes one of two forms. Either the claim is that NSD leads to the inappropriate devaluation of humans (Cronon 1996; Pollan 1991), insofar as it "leaves precisely nowhere for human beings actually to make their living from the land" (Cronon 1996, p. 13) and so conceives of humans as unnatural and unethical invaders (White 1996), or it is that NSD leads to the inappropriate devaluation of non-pristine environments, which are taken to be 'spoiled' by human influence and so less-than-natural and less valuable (Berry 1995; Cronon 1996). In either form, this argument is often directed at the dualistic wilderness ethic, according to which what is best, from an environmental-ethical perspective, is to minimize human influence on the environment and to protect pristine natural environments from non-natural human influence. Crucially, the wilderness ethic depends on a sharp separation of nature from society, sometimes with physical

\footnotetext{
${ }^{9}$ It is not always clear whether critics object to classificatory NSD. If critics of NSD intend to object to classificatory NSD, then our argument functions as an objection. If critics intend only to object to causal NSD, then our argument in this section functions as a call for greater conceptual clarity in arguments against NSD. We think the former is a plausible interpretation of some critics' arguments, but either way, our argument more importantly illustrates the value-flexibility of a scientific practice, as well as how the practice's value-flexibility is responsive to the field's requirements and goals.

10 Granted, it is not as clear that Leopold's target was, or was exclusively, classificatory NSD. On the one hand, Leopold objected to foresters who were "quite content to grow trees like cabbages, with cellulose as the basic forest commodity," and with little regard for ecological causal factors (Leopold 1949, p. 221). "With little regard for ecological causal factors" suggests causal NSD. On the other hand, Leopold contrasted "man the conqueror" with "man the biotic citizen" (Leopold 1949 , p. 223) a distinction both of function and of membership. The distinction of membership suggests classificatory NSD.
}

barriers, regulations, or at least lines on a map - in short, classificatory NSD.

However, despite these criticisms of classificatory NSD, in SES research it is a tool for avoiding causal NSD, which is objectionable on environmental-ethical grounds for other reasons. In particular, classificatory NSD, via SES researchers' coupled-model framework, facilitates tractable empirical research on social-ecological interactions. This research reveals interdependencies between nature and society, conceptualized as distinct subsystems of an overarching SES, rather than as exogenous disturbances to each other, which is what causal NSD would imply. SES research thus demonstrates that devaluing nature may lead to undesirable social outcomes, insofar as people depend on ecosystem services for their well-being (e.g., Rockström et al., 2009). At the same time, SES research can also reveal that crowding out the proper valuation of society may lead to undesirable ecological outcomes, because, for example, the efficacy of conservation often depends on a degree of perceived legitimacy in affected communities (e.g., González et al., 2008; Young et al., 2016). Moreover, SES research can reveal both of these facts simultaneously and so facilitate the proper valuation of both nature and society, insofar as what benefits nature benefits society and vice versa. If anything, the interdependencies that SES research reveals, and that causal NSD would obscure, make it difficult to devalue either nature or society entirely.

Classificatory NSD in SES research is laden with non-epistemic values. It is, after all, motivated by the non-epistemic aim of improving environmental outcomes. Yet this case study demonstrates that classificatory NSD, at least within the narrow context of SES researchers' conceptual modelling practice, is not tied to any one way of valuing nature or society. ${ }^{11}$ First of all, in much the same way that the monetization of nature does not always crowd out certain ways of valuing nature, classificatory NSD does not always crowd out the proper valuation of either nature or society. Of course, win-win scenarios for both nature and society are not always possible in conservation (Hirsch et al., 2010; McShane et al., 2011). It would, therefore, be a problem if classificatory NSD always required the equal valuation of nature and society, as that would make SES research less relevant to the difficult decisions of environmental governance. However, when trade-offs between nature and society are unavoidable, SES research can, first, help reveal them by identifying causal interactions between natural and social subsystems (Ban et al., 2013). Also, because SES research keeps nature and society separate in its conceptual models, nature and society can be assigned different values, within the limits suggested above. Classificatory NSD thus facilitates, or avoids crowding out, a variety of unequal valuations of nature and society, reflecting a range of different priorities, as long as neither nature nor society is devalued outright. ${ }^{12}$

Classificatory NSD in SES researchers' conceptual models thus displays a constrained, though consequential, 'flexibility' with respect to certain non-epistemic values. We refer to this feature as value-flexibility to contrast it with value-freedom. A value-flexible scientific practice - such as classificatory NSD in this context or ecosystem health, as we argue below - is value-laden but not committed to any one non-epistemic value. It may, for example, be compatible with any non-epistemic value or, instead, only some

\footnotetext{
11 Classificatory NSD may, however, be objectionable in other contexts. Our argument in this section is specific to the context of SES research.

${ }^{12}$ We say more about both trade-offs and win-win, or 'convergence,' scenarios in Section 3.
} 
subset of non-epistemic values. By contrast, a value-free scientific practice is not value-laden at all. ${ }^{13}$

Value-flexibility promises a degree of methodological freedom without requiring true value-freedom, but as we argue next through a case study of ecosystem health assessment, valueflexibility alone is insufficient for avoiding all worries about crowding out.

\subsection{Assessing ecosystem health}

Assessing the health of ecological systems has a long history. ${ }^{14}$ Early in the twentieth century, when communities were conceived as superorganisms, assessing their health and pathology seemed natural: ecologists, like medical doctors, could offer diagnosis and prognosis for their diseased superorganismal patients (Adams, 1913). During mid-century, Leopold's popular idea of the land health in A Sand County Almanac (1949) became a mainstay of the environmental movement and environmental ethics. But it was in the late 1980s, when ecological health entered the burgeoning environmental sciences, that its discussion becomes relevant for this article.

Combining Leopold's conservationism with the new systems ecology (Holling 1973; Odum et al., 1979), environmental scientists at this time championed ecosystem health as a foundational concept for environmental management. They saw it as helpful for integrating disparate environmental monitoring and assessment practices that spanned the social, natural, and health sciences. As Schaeffer et al. (1988) wrote in a seminal article,

Environmental decision making is limited and is often fundamentally flawed, because of the inability to relate available data in an ecosystem context. [...] Physicians, as diagnosticians, provide a model for the environmental biologist monitoring the health of an ecosystem. The diagnostician does not collect data without a purpose. Testing is done to measure specific parameters which have known ranges, indicating the state of health. Environmental biologists must approach ecosystem analysis in the same way. $(1988,445)$

One aim of ecosystem health science was to create a diagnostic manual summarizing the aetiology of ecosystem degradation, providing straightforward guidance to managers as they attempted to improve health by alleviating "disease," "dysfunction," or "distress syndrome" (Costanza et al., 1992; Costanza and Mageau 1999; Rapport et al., 1998). This represented an intentional break from past management objectives that emphasized compositional restoration, such as the return to a "natural" species composition. In contrast, ecosystem health was functionally defined, a healthy ecosystem being one that possessed certain capacities, such as for resilience in the face of damage and for supporting ecosystem services, like nutrient cycling or waste absorption. Although controversy remains, as discussed below, the project was successful insofar as ecosystem health assessments are now a staple of environmental science (as evidenced by journals like Ecosystem Health and Sustainability).

\footnotetext{
${ }^{13}$ We say more about the types of research questions that the concept of valueflexibility could inspire below.

14 Aspects of this history are described in Rapport et al. (1998), Scoville (2011), Loo (2011) and Inkpen (2017b).

15 Besides value-ladenness, there are other potential issues with ecosystem health concepts, such as whether this use of health is metaphorical, that have long histories of debate (see: Calow 1992; Callicott 1995; Jamieson 1995; Shrader-Frechette 1997; McShane 2004; Odenbaugh 2010). We will not discuss them here.
}

What makes the discussion of ecosystem health assessments relevant for our purpose is their value-ladenness. ${ }^{15}$ Proponents of ecosystem health assessment are explicit that value judgments-judgements that certain things are good and bad for an ecosystem-are unavoidable when defining ecosystem health (Rapport 1989). But many critics are not primarily concerned with value-ladenness per se. ${ }^{16}$ They are concerned that ecosystem health assessments crowd out the discussion of non-epistemic values. Specifically, that ecosystem health is defined in a way that presupposes answers to questions of value that are themselves the better locus of discussion and debate.

This is sometimes framed in terms of a misuse of the authority of science: empirical findings are reported as fact without acknowledging the normative assumptions on which the findings depend. Lackey in a review of ecosystem health writes that, "The most pervasive misuse of ecosystem health is insertion of personal values under the guise of scientific impartiality," and that, "options for resolving the many ecological policy issues we face depend on the concept of ecosystem health, but ecosystem health is based on controversial, value-based assumptions that masquerade as science" (Lackey 2001).

Consider a recent claim: that "Microplastics can be ingested by marine organisms and have the potential to bioaccumulate and threaten ecosystem health" (Hurley et al., 2018). If ecosystem health is defined in a value-laden way, critics contend, then this statistical claim about the connection between microplastics and ecosystem health presupposes an underlying value judgment in the definition of health itself. Using Alexandrova's helpful terminology, claims about ecosystem health are "mixed claims" in that they involve both empirical and normative elements (Alexandrova 2018). The perceived danger about ecosystem health claims is not that they are mixed, but that inattention to the normative character of these claims presents them as if the underlying normative judgments are uncontroversial or undebatable. A discussion of nonepistemic value is crowded out by science: in order for ecosystem health to be operationalized, underlying value-judgments about what is good for an ecosystem must be answered in some way. ${ }^{17}$

What does it mean to say that ecosystem health is defined in a value-laden way? Consider McShane's conception of ecosystem health (McShane 2004): an ecosystem's health is "a matter of maintaining the structure and functions that are good for the ecosystem." We determine what is good for an ecosystem, she argues, by asking, "What it would make sense for someone who cared for the ecosystem to want for it for its own sake?" This is a question of value, and depends both on how we define the ecosystem and what we take to be good for such systems in general. As McShane (2004) writes,

if one defines an ecosystem as essentially involving certain characteristic species, then anything that threatens the presence of these species thereby threatens the existence of the ecosystem. However, different species can sometimes be functionally redundant. That is to say, they can perform the same ecosystemic functions, and thus are, from the point of view of certain ecosystemic processes, interchangeable. So if we define the ecosystem not in terms of characteristic species but in terms of, say, energy flow, then the extinction of one species wouldn't threaten the ecosystem as long as something else steps in to perform that same function within the system of energy flow. It's possible, then, that under one definition of the ecosystem, the extinction of a particular species will threaten the very

\footnotetext{
16 Although that worry does arise (see Wilkins 1999).

17 A related concern is raised in Sagoff (2003).
} 
existence of the ecosystem, while under a different definition, the ecosystem wouldn't even be changed by the extinction, much less threatened by it. (McShane 2004, 243)

In addition to how we define an ecological system, there is also a more direct question of what is good for an ecosystem. Is persistence good for an ecosystem? Is increased primary productivity good? Rapport makes this point by drawing attention to how human interests might dictate an answer to what is good for an ecosystem for its own sake:

Specific criteria for ecosystem health are also inevitably influenced by the dominant social and cultural values. For example, the idea that a healthy system is a stable one arises naturally enough in a technocratic society where the importance of control and dependability is paramount. The idea that a healthy system is a productive one also arises naturally in a society oriented toward achieving high levels of economic well-being. (Rapport 1989, 127-8)

The take-away from this is not that ecosystem health is necessarily culturally relative, as Rapport suspects, but only that how we define what is good for an ecosystem is a normative judgement: one based on an underlying philosophical debate about value (if we follow McShane).

Critics, like Lackey, see claims about ecosystem health as crowding out an important discussion of values: such claims will not properly acknowledge the role that values have played and such claims presume answers to questions of value which may be the better locus of discussion and debate. Consider an example from Holland (2000, p. 53), who describes Shell's (UK) proposal to sink the Brent Spar oil platform into the North Sea. As Holland describes,

A major problem with the proposal was the amount of metals contained in the tanks and ballast. In an article published in Nature (1995), Nisbet and Fowler observe that metals abound naturally on the ocean floor, especially around midocean-ridge hydrothermal systems. Accordingly, they argue that the metals of the Brent Spar "would not be out of the ordinary, and indeed might be beneficial as a mimic of vent activity." They claim as a result that "the addition of extra dumped metals would probably act as a nutrient to the local ecosystem."

Depending on how health is defined, and how the normative questions that underlie it are decided (is this good for it or bad?), the new system could be healthier than the old (for example, if the Brent Spar increases the capacity for nutrient cycling and that is considered valuable). Critics contend that such flexibility is a recipe for exploitation. Ecosystem health crowds out the discussion of values that really matters, and problematically oversimplifies environmental decision-making. In this case, the discussion should be about the benefits and costs of Shell's proposal for all those affected (whether human, animal, plant, or ecosystem). Thus, the discussion, critics have maintained, would be better focused on descriptions of the potential impact on ecological systems (such as their functions or composition) and why we value or disvalue those descriptions (recreational, aesthetic, economic, etc.), rather than on notions like ecosystem health which must presume answers.

Are these truly problems? And do they undermine the use of ecosystem health in the environmental sciences? As with our previous case study, this case study reiterates the point that practices in the environmental sciences can be quite flexible with regard to non-epistemic values. But unlike the last case study, where this was an obvious benefit, here the flexibility itself is drawn on to support a worry about exploitation. We take these concerns seriously, but think they warrant a lesson other than rejecting ecosystem health assessments in environmental science.

We think that these worries motivate a lesson regarding the importance of transparency about the value-based decisions that inform practice. And we contend that this transparency must be fostered within the environmental sciences and recognized as an essential component by those evaluating these sciences. Lackey's worries are most compelling within a scientific climate that falsely sees health assessments as if they do not depend on value-based assumptions. It is this climate that allows for health assessments to be exploited by those who insidiously conceal their own interests under the guise of what is presented as impartial science. The lesson is not to reject all practices that involve value-based assumptions, especially those flexible enough to accommodate many different values. We believe that our case studies show that this would require rejecting too much. The lesson is to find ways to help change the scientific climate to one that is appropriately transparent about non-epistemic values (as we discuss further below).

As the previous case study demonstrated, value-flexibility can be a virtue of practices within the environmental sciences. But, as this case study has shown, without also fostering transparency about value-ladenness, this flexibility can itself give rise to exploitation and to worries about crowding out.

\section{Analysis}

We have argued that crowding out does not always occur as critics sometimes contend it does in the environmental sciences, that certain practices in the environmental sciences are sometimes value-flexible, and that value-flexibility needs to be complemented with value-transparency in order to avoid crowding out the very discussion of non-epistemic values. In this section, we explain why value-flexibility matters in the environmental sciences and how value-transparency, along with environmental pragmatism, can help environmental scientists harness value-flexibility.

\subsection{The problem of crowding out in the environmental sciences}

In each of our case studies, scientific practices are laden with non-epistemic values. This is characteristic of the environmental sciences generally, even if it is not unique to them. For example, when the late Michael Soule defined conservation biology in the 1980 s, he defined it partly in terms of a set of normative postulates, such as "ecological complexity is good" and "biotic diversity has intrinsic value" (Soulé 1985). And when Peter Kareiva and Michelle Marvier proposed modifications to Soulé's vision, they did not fundamentally criticize the discipline's value-ladenness but instead proposed alternative or supplementary non-epistemic values, most prominently a higher prioritization of human well-being (Kareiva and Marvier 2012). Moreover, surveys suggest that conservation scientists largely agree about the importance of non-epistemic values to their discipline, even if they sometimes disagree about which non-epistemic values are important (Holmes et al., 2017; Sandbrook et al., 2019). Of course, conservation science is only one discipline, but it is exemplary of how well-accepted and explicit 
non-epistemic value judgments are in the environmental sciences, making these sciences ideal sites for investigating questions about the actual role of non-epistemic values in science and the application of science. ${ }^{18}$ Our question in this article is one such question. Again, do practices in the environmental sciences crowd out any non-epistemic values?

No one should deny that crowding out can happen in the environmental sciences and beyond. We have ourselves given some examples, but many others already exist in the literature. For example, feminist philosophers of science have shown that some scientific practices display gender bias, in some cases resulting in what we would call the crowding out of social values like gender equality (Kourany 2003; Richardson 2010). Other philosophers of science have identified trade-offs between non-epistemic and epistemic values, such as predictive accuracy, affordability, and speed (Elliott and McKaughan 2014; Potochnik 2015). Scientists themselves also sometimes explicitly acknowledge facing tradeoffs between competing non-epistemic values. In conservation science, for example, Sahotra Sarkar (2002) has argued that there are multiple concepts of biodiversity, but that not all of them serve conservation science's goal of maximizing biodiversity preservation under constraints; conservation scientists must therefore choose between different concepts of biodiversity on the basis of the concepts' differing non-epistemic value alignments. And even once conservation scientists choose a concept of diversity, they need to choose an indicator that can represent that diversity. Many indicators are available, from species diversity to life zone diversity, and each aligns with particular non-epistemic values rather than others (Sarkar and Margules 2002).

But arguments that particular scientific practices are associated with particular non-epistemic values typically treat the strength of the association as binary: either there is an association or there is not. However, our case studies show that the association is not binary. We therefore suggest that environmental scientists and their critics should re-direct their attention towards the invariance, so to speak, of the relationships between certain scientific practices and certain non-epistemic values. In other words, we should ask questions such as: How invariant are our practices? ${ }^{19}$ Can they incorporate multiple non-epistemic values? Can they incorporate the non-epistemic values that matter, given the context of their use $?^{20}$ In effect, what critics of monetizing nature, NSD, and ecosystem health argue is that the alleged non-epistemic value

\footnotetext{
18 This is not to say that the environmental sciences are representative of all sciences. What is ideal about the environmental sciences as sites of investigation is, first, that explicit non-epistemic values are easier to study and, second, that disciplines that accept a role for non-epistemic values are more likely to be open to suggestions for how to manage those values.

${ }^{19}$ Consider some possibilities. A scientific practice may, strictly speaking, be value-flexible but also be laden with a particular non-epistemic value in almost all contexts or, instead, most of the time in a single context. Alternatively, a scientific practice may be value-flexible and compatible with a wide, though finite, range of non-epistemic values. Wide-ranging compatibility may, in turn, vary by context. For example, a practice could be largely invariant in one context but hardly at all in another.

20 We thank an anonymous reviewer for challenging us to think more deeply about the relationship between practices and non-epistemic values, and for offering clarifications that help us see this as a matter of invariance across contexts. Although we cannot fully address them here, this invariance raises a host of questions for further exploration. As this reviewer pointed out, one concern may be about the tendency of a certain practice to crowd out certain values, even if it is flexible enough to accommodate many values. They suggested that many arguments against the ecosystem services approach take this form. Our concern in this paper was simply to explain the concept of value flexibility and why it matters, but as this reviewer rightly points out, there are many further questions to address (though we cannot do so here). Another further question, also inspired by this reviewer, is the extent to which we should view value-flexibility, in general, as a scientific virtue.
}

displacements of these practices are invariant enough to produce trade-offs, or crowding-out effects, across many different contexts or consistently in a single context. Our case studies show, instead, that the relationship varies by context and within contexts.

\subsection{Why value-flexibility matters in the environmental sciences}

There are at least two reasons to think that value-flexibility is important to the environmental sciences. First, trade-offs between epistemic and non-epistemic values or between competing nonepistemic values can potentially force environmental scientists to compromise on their epistemic or non-epistemic goals. It is therefore essential for environmental scientists to have an accurate understanding of the value-flexibility, or lack thereof, of their various practices, so that researchers can make informed decisions about competing goals, in some cases avoiding trade-offs altogether.

Second, value-flexibility can allow for a degree of stakeholder choice in environmental policy-making, as required by democratic norms and perhaps environmental science itself. ${ }^{21}$ Pielke's four "idealized roles" for scientists in policy-making can be used to articulate this point (Pielke 2007). The four roles are (1) the "Pure Scientist," (2) the "Science Arbiter," (3) the "Issue Advocate," and (4) the "Honest Broker of Policy Alternatives." According to the Pure Scientist model, scientists should conduct research without any regard for or involvement in policy-making. By contrast, according to the Science Arbiter model, scientists should assist policymakers, albeit while remaining policy-neutral and only answering purely epistemic questions. The Issue Advocate model abandons such neutrality, recommending that scientists advocate particular policies. Finally, according to the Honest Broker model, scientists should, like Science Arbiters, try to be policy-neutral but, unlike Science Arbiters, be willing to answer questions about the connections between epistemic and non-epistemic goals. As Pielke puts it, "[T]he Honest Broker of Policy Alternatives seeks explicitly to integrate scientific knowledge with stakeholder concerns in the form of alternative possible courses of action" (Pielke 2007, p. 17).

Which of these models is most appropriate for the environmental sciences? The Pure Scientist model would be an awkward fit, given that the environmental sciences are often policy-directed. Also, it is difficult to apply the Science Arbiter model to the environmental sciences, because although the model requires engagement with policy-making, it also requires value-free science, which is difficult to come by in the environmental sciences. Environmental scientists are left, then, with the Issue Advocate and Honest Broker models, both of which recommend that scientists deliver value-laden advice to policymakers.

Some environmental scientists appear to endorse the Issue Advocate model, but that position remains controversial (Nelson and Vucetich 2009). For instance, conservation scientists have long debated whether they should advocate policies that protect biodiversity (Marris 2006; Scott et al., 2007), with some critics worrying that advocacy could undermine conservation scientists' credibility (e.g., Lackey 2007). But another worry about the Issue Advocate Model concerns democracy. As Heather Douglas points out with respect to science more generally, "Regardless of which theoretical ideal of democracy one might hold, it is not acceptable for a minority elite to impose their values on the general populace" (Douglas 2005, p. 156). It would indeed be an imposition in the case of the environmental sciences, because it is rarely feasible for stakeholders to exit the relationship by disregarding environmental

\footnotetext{
21 Stakeholders are essential to many aspects of 'sustainability science' (Nagatsu et al. 2020).
} 
scientists' input altogether (see Warren 2011), as stakeholders are typically (at least partly) epistemically dependent on environmental scientists (see Holst and Molander 2014), while at the same time facing complex environmental problems that demand solutions informed by science. Thus, stakeholders are, in a sense, vulnerable to environmental scientists' value judgments and so count as "affected interests," who are, as such, entitled to a degree of influence over the decisions that affect them (see Fung 2013; Goodin 2007; Warren 2017). Of course, these decision-making rights may not extend to scientific research itself (Collins and Evans 2007), but the bare minimum is for stakeholders to decide which non-epistemic values inform policy (Intemann, 2015; Schroeder, 2019), a domain in which environmental scientists have no claim to expertise in the first place, and in which values are frequently contested (Odenbaugh 2003). This minimal democratic requirement rules out the Issue Advocate model and leaves the Honest Broker model as the only option that is applicable to the value-laden environmental sciences but also consistent with democratic norms.

The connection between the Honest Broker model and valueflexibility is that value-flexibility, when available, may serve that model. In particular, a scientific practice that is value-flexible may, in a specified context, be compatible with a plurality of nonepistemic values and so a variety of stakeholder preferences. There is, then, a prima facie democratic reason for environmental scientists to identify and utilize existing instances of valueflexibility and perhaps even to favour value-flexible practices when multiple practices are available, in order to avoid undemocratically 'setting the agenda' on non-epistemic values. Classificatory NSD in SES researchers' conceptual modelling, for instance, leaves the valuation of nature and society open to a range of stakeholder preferences. ${ }^{22}$

Of course, value-flexible practices are not always available, owing to such factors are "distributed epistemic agency" and "generatively entrenched methodological choices," which embed non-epistemic values in the "nooks and crannies" of research in fields such as climate science and biomedicine, where nonepistemic values can consequently become difficult even to identify, let alone modify (Winsberg 2012; Winsberg et al., 2014). Such inscrutability is particularly likely to occur in interdisciplinary research, where value-laden scientific practices and products are iteratively exchanged across disciplinary boundaries, potentially accumulating non-epistemic baggage over time. At the same time, our case studies show that, even under these circumstances (in the highly interdisciplinary environmental sciences), a degree of valueflexibility is sometimes possible. Perhaps even when it is lacking, it should serve as an ideal that scientists sometimes attempt to foster.

\subsection{Harnessing value-flexibility}

If value-flexibility is itself valuable to the environmental sciences, then one might want to know how environmental scientists could better identify and promote it. Here, we reiterate the need for value-transparency and offer another suggestion as well, namely, to adopt some of the methodological precepts of environmental pragmatism, which may encourage environmental scientists and their critics to embrace scientific practices' ties to non-epistemic

\footnotetext{
22 Of course, it is a finite range. And that may be a feature, rather than a bug, of any given value-flexible practice, if it is desirable for the practice to exclude socially unacceptable values. Classificatory NSD, for instance, makes valuing either nature or society at the total expense of the other difficult, and that may be a good thing. What is desirable, then, is not value-flexibility tout court but value-flexibility with specified limits.
}

values without imposing those values upon stakeholders or themselves.

Environmental pragmatists characteristically reject highly theoretical debates in environmental ethics-for example, between anthropocentrism and biocentrism-and the related "top-down" application of environmental-ethical theories to real-world environmental problems (e.g., Light 2009). Their alternative is meant to be 'bottom-up' and practical, with an important prescription being that environmental ethicists should start their work with the empirical fact of environmental-ethical diversity - that is, the fact that not everyone agrees about environmental-ethical theories, and that such disagreement is unlikely to go away(e.g., Minteer and Manning 1999). The task, then, according to environmental pragmatists, is to navigate environmental-ethical diversity in order to improve environmental governance without hoping, against the odds, to eliminate that diversity. Norton's "convergence hypothesis" is a case in point (Norton 1991). According to the hypothesis, environmentalists can, on a case-by-case basis, find common ground regarding policy, even if they disagree about grand environmental-ethical theories.

The convergence hypothesis is controversial (Minteer 2009), but the point that a single policy may, within a specified context, sometimes serve different goals remains useful regardless. Indeed, we suggest an analogous idea, namely, for environmental scientists and others to try to adopt practices that are sufficiently valueflexible for stakeholders with different environmental-ethical positions to converge on. To do so, the key is to avoid ruling out any particular conservation strategy a priori and to redirect efforts towards answering a more pragmatic and empirical question: how effective is a given strategy, in a given context, at achieving a common (democratically-determined) environmental goal or, in case of disagreement, a set of environmental goals? Asking this question may, if coupled with awareness about the possibility of value-flexibility, prompt environmental scientists and others to notice existing instances of value-flexibility through the empirical investigation of a practices' non-epistemic effects.

Of course, carrying out this pragmatic project requires not just value-flexibility but transparency as well. We find Alexandrova's three rules for the use of mixed claims to be a good start and we endorse and recount them here, using ecosystem health as an illustration (Alexandrova 2018). First, value presuppositions need to be made explicit. This involves stating explicitly how a measure of ecosystem health is informed by underlying value presuppositions about what ecosystem health consists in. Second, we have to work to determine whether a particular measure of ecosystem health is good at tracking health on every plausible theory of ecosystem health (or is, alternatively, invariant to different underlying conceptions of ecosystem health). Since there are a plethora of different conceptions of ecosystem health, this seems unlikely. So, third, we have to choose the ecosystem health measure that best fits with the underlying value commitments of experts, policy makers, and the people (and animals, etc.) that will be affected by management decisions that are informed by the measure. In short, we need to begin with transparency and end with the pragmatic question. The role of value-flexibility, then, is to provide more leeway in answering the pragmatic question.

\section{Conclusion: efficacious environmental science}

In the Introduction, we claimed that, in addition to the question of epistemic success that MacLeod and Nagatsu (2016) address, it is critical to interrogate non-epistemic values in the environmental sciences, including the question of whether practices in the environmental sciences crowd out non-epistemic values, since overall 
success in the environmental sciences is never merely a question about producing science with desirable epistemic values.

However, if success in the environmental sciences is defined as both non-epistemic and epistemic, then we are led to the worry that epistemically successful practices may crowd out socially significant non-epistemic values. This is a legitimate concern with practical implications for the environmental sciences, but our case studies show that crowding out is not always a debilitating problem. First, our case study on the monetization of nature among ecological economists demonstrates that crowding out particular non-epistemic values does not always occur; instead, it is sensitive to context. Second, our case study of NSD in SES research demonstrates that a scientific practice can be value-flexible, even in a given context. Third, our case study of ecosystem health assessment demonstrates that, while value-flexibility alone cannot solve the problem of crowding out, it may if it is paired with valuetransparency.

To be clear, nothing we have argued suggests that crowding out is never a problem. We have, however, argued that there is sometimes reason for environmental scientists to try to exploit and promote value-flexibility when possible in order to manage tradeoffs between competing values, and abide by democratic norms that require stakeholder involvement in setting the non-epistemic aims of policy-directed science. Alexandrova's recommendations, especially regarding transparency, can help with accomplishing this task. So too can some of the methodological precepts of environmental pragmatism, which directs us to work with rather than against value diversity and to shift our attention to empirical questions about how well a given practice can in fact promote a given non-epistemic value in a given context.

\section{References}

Adams, C. C. (1913). Guide to the study of animal ecology. London: Macmillan.

Agrawal, A., \& Ostrom, E. (2006). Political science and conservation biology: A dialog of the deaf. Conservation Biology, 20(3), 681-682.

Alberti, M., Asbjornsen, H., Baker, L. A., Brozovic, N., Drinkwater, L. E., Drzyzga, S. A Jantz, C. A., Fragoso, J., Holland, D. S., Kohler, T., Tim), A., Liu, J., Jack), McConnell, W. J., Maschner, H. D. G., Millington, J. D. A., Monticino, M., Podestá, G., \& Pontius, R. G. (2011). Research on coupled human and natural systems (CHANS): Approach, challenges, and strategies. The Bulletin of the Ecological Society of America, 92(2), 218-228.

Alexandrova, A. (2018). Can the science of well-being be objective? The British Journal for the Philosophy of Science, 69(2), 421-445.

Anderies, J. M., Janssen, M. A., \& Ostrom, E. (2004). A framework to analyze the robustness of social-ecological systems from an institutional perspective. Ecology and Society, 9(1), art18.

Anderson, E. (1990). The ethical limitations of the market. Economics and Philosophy, 6, 179-205.

Anderson, E. (1993). Value in ethics and economics. Cambridge, M.A.: Harvard University Press.

Ban, N. C., Mills, M., Tam, J., Hicks, C. C., Klain, S., Stoeckl, N., Bottrill, M. C., Levine, J. Pressey, R. L., Satterfield, T., \& Chan, K. M. (2013). A social-ecological approach to conservation planning: Embedding social considerations. Frontiers in Ecology and the Environment, 11(4), 194-202.

Barbier, E. B. (2011). Capitalizing on nature: Ecosystems as natural assets. Cambridge: Cambridge University Press.

Bennett, N. J., Blythe, J., Tyler, S., \& Ban, N. C. (2016). Communities and change in the anthropocene: Understanding social-ecological vulnerability and planning adaptations to multiple interacting exposures. Regional Environmental Change 16(4), 907-926.

Berkes, F., \& Folke, C. (Eds.). (1998). Linking social and ecological systems: Management practices and social mechanisms for building resilience. Cambridge: Cambridge University Press.

Berry, W. (1995). The obligation of care. Sierra, 80(5), 62-67, 101.

Binder, C. R., Hinkel, J., Bots, P. W. G., \& Pahl-Wostl, C. (2013). Comparison of frameworks for analyzing social-ecological systems. Ecology and Society, 18(4), art26.

Brown, M. J. (2013). Values in science beyond underdetermination and inductive risk. Philosophy of Science, 80(5), 829-839.

Callicott, J. B. (1995). The value of ecosystem health. Environmental Values, 4(4), 345 361.

Calow, P. (1992). Can ecosystems be healthy? Critical consideration of concepts. Journal of Aquatic Ecosystem Health, 1(1), 1-5.
Colding, J., \& Barthel, S. (2019). Exploring the social-ecological systems discourse 20 years later. Ecology and Society, 24(1). art2.

Collins, S. L., Carpenter, S. R., Swinton, S. M., Orenstein, D. E., Childers, D. L., Gragson, T. L., Grimm, N. B., Grove, J. M., Harlan, S. L., Kaye, J. P., Knapp, A. K., Kofinas, G. P., Magnuson, J. J., McDowell, W. H., Melack, J. M., Ogden, L. A., Robertson, G. P. Smith, M. D. \& Whitmer, A. C. (2011). An integrated conceptual framework for long-term social-ecological research. Frontiers in Ecology and the Environment, 9(6), 351-357.

Collins, H. M., \& Evans, R. (2007). Rethinking expertise. Chicago: University of Chicago Press.

Costanza, R., de Groot, R., Sutton, P., van der Ploeg, S., Anderson, S. J., Kubiszewski, I., Farber, S., \& Turner, R. K. (2014). Changes in the global value of ecosystem services, Global Environmental Change, 26, 152-158.

Costanza, R., d’Arge, R., de Groot, R., Farber, S., Grasso, M., Hannon, B., Limburg, K., Naeem, S., O’Neill, R. V., Paruelo, J., Raskin, R. G., Sutton, P., \& van den Belt, M. (1997). The value of the world's ecosystems services and natural capital. Nature, 387, 253-260.

Costanza, R., \& Mageau, M. (1999). What is a healthy ecosystem? Aquatic Ecology, 33(1), 105-115.

Costanza, R., Norton, B. G., \& Haskell, B. D. (1992). Ecosystem health: New goals for environmental management. Washington: Island Press.

Cronon, W. (1996). The trouble with wilderness: Or, getting back to the wrong nature. Environmental History, 1(1), 7-28.

Daily, G. C. (Ed.). (1997). Nature's services: Societal dependence on natural ecosystems. Washington, D.C: Island Press.

Dasgupta, P. (2010). Nature's role in sustaining economic development. Philosophical Transactions of the Royal Society B, 365, 5-11.

DesRoches, C. T. (2018). What is natural about natural capital during the anthropocene? Sustainability, 10, 806.

DesRoches, C. T. (2019). On the concept and conservation of critical natural capital. International Studies in the Philosophy of Science, 32(3-4), 207-228.

DesRoches, C. T. (2020). The preservation paradox and natural capital. Ecosystem Services: Science, Policy and Practice, 4, 101058.

Douglas, H. (2005). Inserting the public into science. In S. Maasen, \& P. Weingart (Eds.), Democratization of expertise? Exploring novel forms of scientific advice in political decision-making (pp. 153-169). Dordrecht: Springer.

Douglas, H. (2013). The value of cognitive values. Philosophy of Science, 80(5), $796-$ 806

Elliott, K. C., \& McKaughan, D. J. (2014). Nonepistemic values and the multiple goals of science. Philosophy of Science, 81(1), 1-21.

Elliott, K. C., \& Steel, D. (Eds.). (2017). Current controversies in values and science. New York: Taylor \& Francis.

Elliott, K. C., \& Willmes, D. (2013). Cognitive attitudes and values in science. Philosophy of Science, 80(5), 807-817.

Farley, J., \& Costanza, R. (2010). Payments for ecosystem services: From local to global. Ecological Economics, 69(11), 2060-2068.

Fung, A. (2013). The principle of affected interests: An interpretation and defense. In J. H. Nagel, \& R. M. Smith (Eds.), Representation: Elections and beyond. Philadelphia: University of Pennsylvania Press.

Georgescu-Roegen, N. (1971). The Entropy Law and the economic process. Cambridge, M.A.: Harvard University Press.

Gómez-Baggethun, E., \& Ruiz-Pérez, M. (2011). Economic valuation and the commodification of ecosystem services. Progress in Physical Geography: Earth and Environment, 35(5), 613-628.

González, J. A., Montes, C., Rodríguez, J., \& Tapia, W. (2008). Rethinking the galapagos islands as a complex social-ecological system. Ecology and Society, 13(2), 13.

Goodin, R. E. (2007). Enfranchising all affected interests, and its alternatives. Philosophy E' Public Affairs, 35(1), 40-68.

Heal, G. (2000a). Nature and the marketplace: Capturing the value of ecosystem services. Washington, D.C: Island Press.

Heal, G. (2000b). Valuing ecosystem services, Ecosystems, 1, 24-30.

Heemskerk, M., Wilson, K., \& Pavao-Zuckerman, M. (2003). Conceptual models as tools for communication across disciplines. Conservation Ecology, 7(3).

Helm, D. (2015). Natural capital: Valuing the planet. New Haven: Yale University Press.

Hinkel, J., Bots, P. W. G., \& Schlüter, M. (2014). Enhancing the Ostrom socialecological system framework through formalization. Ecology and Society, 19(3).

Hirsch, P. D., Adams, W. M. Brosius, J. P. Zia, A., Bariola, N., \& Dammert, J. L. (2010). Acknowledging conservation trade-offs and embracing complexity: Conservation trade-offs and complexity. Conservation Biology, 25(2), 259-264.

Holland, A. (2000). Ecological integrity and the Darwinian paradigm. In D. Pimentel, L. Westra, \& R. F. Noss (Eds.), Ecological integrity: Integrating environment, conservation, and health. Washington: Island Press.

Holling, C. S. (1973). Resilience and stability of ecological systems. Annual Review of Ecology and Systematics, 4(1), 1-23.

Holmes, G., Sandbrook, C., \& Fisher, J. A. (2017). Understanding conservationists' perspectives on the new-conservation debate: Perspectives on the New Conservation. Conservation Biology, 31(2), 353-363.

Holst, C., \& Molander, A. (2014). Epistemic democracy and the accountability of experts. In C. Holst (Ed.), Expertise and democracy (pp. 13-35). Oslo: ARENA.

Hurley, R., Woodward, J., \& Rothwell, J. J. (2018). Microplastic contamination of river beds significantly reduced by catchment-wide flooding. Nature Geoscience, 11(4), 251-257. 
Inkpen, S. A. (2017a). Are humans disturbing conditions in ecology? Biology and Philosophy, 32, 51-71.

Inkpen, S. A. (2017b). Demarcating nature, defining ecology: Creating a rationale for the study of nature's "primitive conditions". Perspectives on Science, 25(3), 355392.

Inkpen, S. A., \& DesRoches, C. T. (2020). When ecology needs economics and economics needs ecology: Interdisciplinary exchange during the anthropocene. Ethics, Policy \& Environmenthttps://doi.org/10.1080/21550085.2020.1848182.

Intemann, K. (2015). Distinguishing between legitimate and illegitimate values in climate modeling. European Journal for Philosophy of Science, 5(2), 217-232.

Jamieson, D. (1995). Ecosystem health: Some preventive medicine. Environmental Values, 4(4), 333-344.

Kareiva, P., \& Marvier, M. (2012). What is conservation science? BioScience, 62(11), 962-969.

Kareiva, P., Tallis, H., Ricketts, T. H., Daily, G. C., \& Polasky, S. (2011). Natural capital: Theory and practice of mapping ecosystem services. Oxford: Oxford University Press.

Kourany, J. A. (2003). A philosophy of science for the twenty-first century. Philosophy of Science, 70(1), 1-14.

Kuhn, T. S. (1962). The structure of scientific revolutions. Chicago: University of Chicago press.

Kuhn, T. S. (1977). Objectivity, value judgment, and theory choice. In The essential tension. Chicago: University of Chicago Press.

Lackey, R. T. (2001). Values, policy, and ecosystem health. BioScience, 51(6), 437-443.

Lackey, R. T. (2007). Science, scientists, and policy advocacy. Conservation Biology, 21(1), 12-17. https://doi.org/10.1111/j.1523-1739.2006.00639.x.

Leopold, A. (1949). A Sand county almanac. New York: Oxford University Press.

Light, A. (2009). Does a public environmental philosophy need a convergence hypothesis? In B. A. Minteer (Ed.), Nature in common?: Environmental ethics and the contested foundations of environmental policy Philadelphia: Temple University Press.

Liu, J., Dietz, T., Carpenter, S. R., Folke, C., Alberti, M., Redman, C. L., Schneider, S. H., Ostrom, E., Pell, A. N., Lubchenco, J., Taylor, W. W., Ouyang, Z., Deadman, P., Kratz, T., \& Provencher, W. (2007). Coupled Human and Natural Systems, 36(8), 11.

Longino, H. E. (1990). Science as social knowledge: Values and objectivity in scientific inquiry. New Jersey: Princeton University Press.

Loo, C. (2011). Ecosystem health reconsidered (Order No. 3475154). Available from ProQuest Dissertations \& Theses Global. (900302462). Retrieved from https:// search-proquest-com.berlioz.brandonu.ca/docview/900302462? accountid=9705.

MacLeod, M., \& Nagatsu, M. (2016). Model coupling in resource economics: Conditions for effective interdisciplinary collaboration. Philosophy of Science, 83(3), $412-433$.

Marris, E. (2006). Should conservation biologists push policies? Nature, 442(7098), $13-13$.

Martinez-Alier, J., \& Røpke, I. (Eds.). (2008a). Recent developments in ecological economics I northampton: Edward elgar publishing.

Martinez-Alier, J., \& Røpke, I. (Eds.). (2008b). Recent developments in ecological economics II. Northampton: Edward Elgar Publishing.

McShane, K. (2004). Ecosystem health. Environmental Ethics, 26(3), 227-245.

McShane, T. O., Hirsch, P. D., Trung, T. C., Songorwa, A. N., Kinzig, A., Monteferri, B. Mutekanga, D., Thang, H. V., Dammert, J. L., Pulgar-Vidal, M., Welch-Devine, M., Peter Brosius, J., Coppolillo, P., \& O'Connor, S. (2011). Hard choices: Making trade-offs between biodiversity conservation and human well-being. Biological Conservation, 144(3), 966-972.

Meyer, J. M. (1999). Interpreting nature and politics in the history of Western thought: The environmentalist challenge. Environmental Politics, 8(2), 1-23.

Minteer, B. A. (2009). Unity among environmentalists? Debating the values- policy link in environmental ethics. In B. A. Minteer (Ed.), Nature in common?: Environmental ethics and the contested foundations of environmental policy (pp. 3-17). Philadelphia: Temple University Press.

Minteer, B. A., \& Manning, R. E. (1999). Pragmatism in environmental ethics: Democracy, pluralism, and the management of nature. Environmental Ethics, 21(2), 191-207.

Moore, J. W. (2016a). Introduction: Anthropocene or capitalocene? Nature, history, and the crisis of capitalism. In J. W. Moore (Ed.), Anthropocene or capitalocene? Nature, history, and the crisis of capitalism (pp. 1-11). Oakland: PM Press.

Moore, J. W. (2016b). The rise of cheap nature. In J. W. Moore (Ed.), Anthropocene or capitalocene? Nature, history, and the crisis of capitalism (pp. 78-115). Oakland: PM Press.

Nagatsu, M., Davis, T., DesRoches, C. T., Koskinen, I., MacLeod, M., Stojanovic, M., \& Thorén, H. (2020). Philosophy of science for sustainability science. Sustainability Science, 1-11.

Nelson, M. P., \& Vucetich, J. A. (2009). On advocacy by environmental scientists: What, whether, why, and how. Conservation Biology, 23(5), 1090-1101.

Norton, B. G. (1991). Toward unity among environmentalists. Oxford: Oxford University Press.

Odenbaugh, J. (2003). Values, advocacy and conservation biology. Environmental Values, 12(1), 55-69.

Odenbaugh, J. (2010). On the very idea of an ecosystem. In New waves in metaphysics (pp. 240-258). London: Palgrave Macmillan.
Odum, E. P., Finn, J. T., \& Franz, E. H. (1979). Perturbation theory and the subsidystress gradient. BioScience, 29(6), 349-352.

Ostrom, E. (2007). A diagnostic approach for going beyond panaceas. Proceedings of the National Academy of Sciences, 104(39), 15181-15187.

Pielke, R. A. (2007). The honest broker: Making sense of science in policy and politics. Cambridge: Cambridge University Press.

Pollan, M. (1991). Second nature: A gardener's education. New York: Grove Press.

Potochnik, A. (2015). The diverse aims of science. Studies In History and Philosophy of Science Part A, 53, 71-80.

Radin, M. J. (1996). Contested commodities. Cambridge, M.A.: Harvard University Press.

Rapport, D. J. (1989). What constitutes ecosystem health? Perspectives in Biology and Medicine, 33(1), 120-132.

Rapport, D., Costanza, R., Epstein, P. R., Gaudet, C., \& Levins, R. (1998). Ecosystem health. Malden, Mass: Blackwell Science.

Richardson, S. S. (2010). Feminist philosophy of science: History, contributions, and challenges. Synthese, 177(3), 337-362.

Rockström, J., Steffen, W., Noone, K., Persson, Å., Chapin, F. S., Lambin, E. F., Lenton, T. M., Scheffer, M., Folke, C., Schellnhuber, H. J., Nykvist, B., de Wit, C. A., Hughes, T., van der Leeuw, S., Rodhe, H., Sörlin, S., Snyder, P. K., Costanza, R. Svedin, U., \& Foley, J. A. (2009). A safe operating space for humanity. Nature, 461(7263), 472-475.

Røpke, I. (2005). Trends in the development of ecological economics: From the late 1980s until the early 2000s. Ecological Economics, 55(2), 262-290.

Rudner, R. (1953). The scientist qua scientist makes value judgments. Philosophy of Science, 20(1), 1-6.

Sagoff, M. (2003). The plaza and the pendulum: Two concepts of ecological science. Biology and Philosophy, 18(4), 529-552.

Sandbrook, C., Fisher, J. A., Holmes, G., Luque-Lora, R., \& Keane, A. (2019). The global conservation movement is diverse but not divided. Nature Sustainability, 2(4), 316-323.

Sandel, M. J. (2012). What money can't buy: The moral limits to markets. New York: Farrar, Straus, and Giroux.

Sarkar, S. (2002). Defining "biodiversity". Assessing Biodiversity: The Monist, 85(1), $131-155$.

Sarkar, S., \& Margules, C. (2002). Operationalizing biodiversity for conservation planning. Journal of Biosciences, 27(4), 299-308.

Satz, D. (2010). Why some things should not be for sale: The moral limits of markets. Oxford: Oxford University Press.

Schaeffer, D. J., Herricks, E. E., \& Kerster, H. W. (1988). Ecosystem health: I. Measuring ecosystem health. Environmental Management, 12(4), 445-455.

Schlüter, M., McAllister, R. R. J., Arlinghaus, R., Bunnefeld, N., Eisenack, K., Hölker, F. Milner-Gulland, E. J., \& Müller, B. (2012). New horizons for managing the environment: A review of coupled social-ecological systems modeling. Natural Resource Modeling, 25(1), 219-272.

Schroeder, S. Andrew (2019). Democratic values: A better foundation for public trust in science. The British Journal for the Philosophy of Science. https://doi.org/ 10.1093/bjps/axz023.

Scott, J. M., Rachlow, J. L., Lackey, R. T., Pidgorna, A. B., Aycrigg, J. L., Feldman, G. R., Svancara, L. K., Rupp, D. A., Stanish, D. I., \& Steinhorst, R. K. (2007). Policy advocacy in science: Prevalence, perspectives, and implications for conservation biologists. Conservation Biology, 21(1), 29-35. https://doi.org/10.1111/j.15231739.2006.00641.x.

Scoville, J. M. (2011). Environmental values, animals, and the ethical life (Order No. 3496684). Available from ProQuest Dissertations \& Theses Global (920150972).Retrievedfrom https://search-proquest-com.berlioz.brandonu.ca/ docview/920150972? accountid=9705.

Shrader-Frechette, K. (1997). Ecological risk assessment and ecosystem health: Fallacies and solutions. Ecosystem Health, 3(2), 73-81.

Soulé, M. E. (1985). What is conservation biology? BioScience, 35(11), 727-734.

Victor, P. (2020). Cents and nonsense: A critical appraisal of the monetary valuation of nature. Ecosystem Services, 42, 1-8.

Walzer, M. (1983). Spheres of justice: A defense of pluralism and equality. New York: Basic Books.

Warren, M. E. (2011). Voting with your feet: Exit-based empowerment in democratic theory. American Political Science Review, 105(4), 683-701.

Warren, M. E. (2017). The all affected interests Principle in democratic Theory and practice (working paper 145; the all affected interests principle in democratic theory and practice). Institute for Advanced Studies.

White, R. (1996). “Are you an environmentalist or do you work for a living?": Work and nature. In W. Cronon (Ed.), Uncommon ground: Rethinking the human place in nature (pp. 171-185). New York: Norton.

Wilkins, D. A. (1999). Assessing ecosystem health. Trends in Ecology \& Evolution, $14(2), 69$.

Winsberg, E. (2012). Values and uncertainties in the predictions of global climate models. Kennedy Institute of Ethics Journal, 22(2), 111-137.

Winsberg, E., Huebner, B., \& Kukla, R. (2014). Accountability and values in radically collaborative research. Studies In History and Philosophy of Science Part A, 46, 1623.

Young, J. C., Searle, K., Butler, A., Simmons, P., Watt, A. D., \& Jordan, A. (2016). The role of trust in the resolution of conservation conflicts. Biological Conservation, 195, 196-202. 